\title{
Law spurs regulators to heed patients' priorities
}

\section{US FDA to consider risks and benefits more explicitly in drug approvals.}

\section{BY AMY MAXMEN}

$\mathrm{W}$ hen the prescription weight-loss drug Belviq (lorcaserin) was approved on 27 June, onlookers wondered what had changed. Two years ago, the US Food and Drug Administration (FDA) rejected the drug because of the possibility that it can damage heart valves, like similar anti-obesity drugs. Had the agency revised its thinking after hearing pleas from obese people who wanted the drug, deciding that the benefits outweighed the risks? "Right now, it's impossible for us to understand how the benefit-risk calculation was conducted," says Marc Boutin, executive vice-president of the National Health Council, a patient-advocacy group in Washington DC.

That situation is due to change. The agency is working to establish a framework that formally takes into account the trade-offs between risks and benefits - including the way they are prioritized by patients. Patient and industry groups hope that the approach will result in greater transparency for FDA reviews, and perhaps more drug approvals for a wider array of patient populations. On 9 July, the agency's efforts received a further push, when President Barack Obama signed into law the FDA Safety and Innovation Act, which, among many other provisions, orders the agency to forge ahead with the framework.

If the FDA's procedures are in place by October 2013 as planned, the agency should be better equipped to explain why it approved a drug such as Belviq for a specific group of people in the population. "Let's make the risks and benefits as clear as a food label, so the decision can be articulated in a way that people understand," says Boutin.

One challenge is how to incorporate patients' views. Although patients and their advocates sometimes speak briefly at FDA advisory meetings, they may not represent all patients, and it is unclear how reviewers take their views into account. Boutin notes that the priorities of sick people can be very different from what healthy people assume them to be. For example, he says, FDA reviewers might assume that patients with psoriasis want treatments that are most effective at shrinking the size of their skin lesions, regardless of where they occur. But in fact, he says, people with psoriasis care most about eliminating lesions on their faces.

To gain a better sense of patients' views, the FDA will hold 20 disorder-specific meetings

\section{"Let's make} the risks and benefits as clear as a food label." with patient groups over the next five years. One way of structuring the meetings, suggested by the National Health Council, would be to divide people into groups who may have common views about the risk-benefit trade-offs, such as those with progressively worsening conditions, and those in their final years of life. "We'll experiment until we get it right," says Janet Woodcock, head of the FDA's drugapproval centre.

Boutin says that he expects drug approvals under the new system to better reflect the risk-benefit trade-offs in the minds of people needing the drugs, not those reviewing them. Because patients with crippling conditions may tolerate higher risks than those with milder problems, this could mean that medicines for certain severe illnesses - especially diseases with few treatment options - have a greater chance of being approved, he says.
However, Woodcock says that the FDA isn't aiming to alter approval rates, but rather to create a more consistent and transparent approval process.

Industry will benefit, says Peter Greenleaf, president of MedImmune - the biologics arm of pharmaceutical company AstraZeneca - based in Gaithersburg, Maryland. Greenleaf says that the mandate to create a risk-benefit framework is one of the most important parts of the new FDA law. "Hopefully, this will allow for a higher degree of alignment between how industry assesses the risks and benefits of a drug and how the FDA does, so that we're not just shooting in the dark," he says. That would allow companies to streamline their studies, Greenleaf adds.

However, the FDA's pilot framework won't weigh up risks and benefits with numbers, as some stakeholders had hoped, but will instead assess them in words. The Centre for Innovation in Regulatory Science (CIRS) in London has spent years constructing quantitative riskbenefit assessment models, and drug companies already use them in pre-approval market research. In theory, such models provide more consistent results between drug-approval cases because they are less subjective. But Woodcock says that models with too many numbers would hamper the FDA's efforts to communicate its decisions to the public. "You start losing people," she says.

A few years ago, Europe's drug-regulatory body, the London-based European Medicines Agency, piloted the use of quantitative models, but earlier this year gave them up in favour of a qualitative approach. But Stuart Walker of the CIRS predicts that regulatory agencies around the world will eventually shift to numerical models. Still, he adds, "I think building an explicit framework is a super first step". -

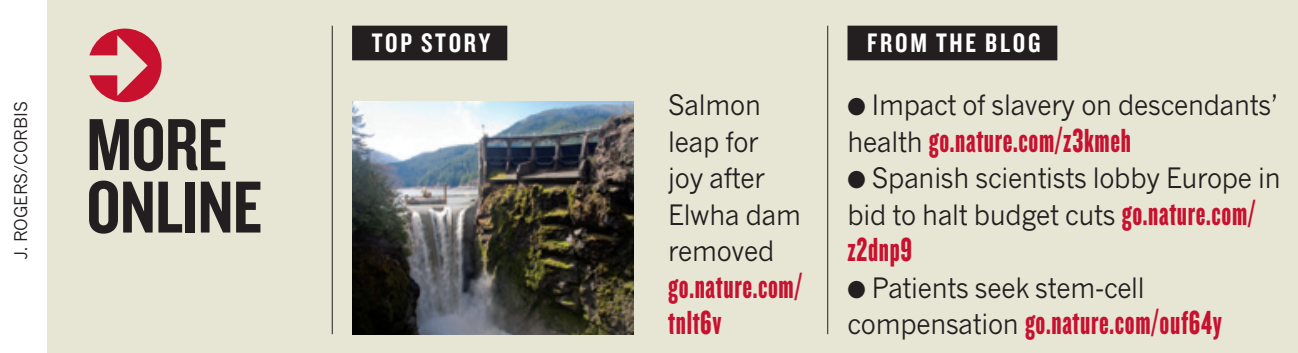

\section{JOIN THE DEBATE}

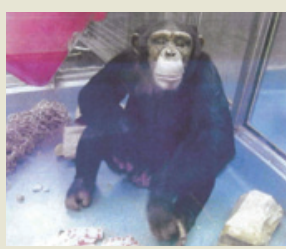

Is it time for the NIH research chimps to be retired? go.nature. com/31cwoj 